\title{
KLASIFIKASI AKASARA JAWA DENGAN CNN
}

\author{
Edo Prasetyo N.A. Wijaya ${ }^{1}$, Hendrawan Armanto ${ }^{2}$, Lukman Zaman $^{3}$ \\ ${ }_{1,2,3}$ Teknologi Informasi, Institut Sains dan Teknologi Terpadu Surabaya (iSTTS) \\ Jl. Ngagel Jaya Tengah No.73-77, Baratajaya, Kec. Gubeng, Kota SBY, Jawa Timur 60284 \\ 085732329074 \\ E-mail: ${ }^{1}$ prasejaya@gmail.com
}

\begin{abstract}
It is common knowledge that CNN is a significant method in image classification. This is because CNN can classify Latin letters with a high degree of accuracy. Lenet5 in CNN is tasked with converting 2D features from an image into a convolutional network continuously. CNN architecture consists of several layers, including the Convolution Layer, Relu layer, Subsampling layer, Fully Connected Layer. In this research, CNN is used to classify Javanese script images into 20 classes. These classes include ha, na, ca, ra, ka, da, ta, wa, la, pa, dha, ja, yes, nya, ma, ga, ba, tha, nga. Javanese script used in this research is Ngalena Javanese script. The precision values for each class range from 0.5 to 0.6 .
\end{abstract}

\section{Keywords: Classification, Convolution Neural Network, Javanesse Letter}

\section{PENDAHULUAN}

CNN adalah sebuah jaringan saraf tiruan yang dapat mengekstraksi fitur topologis dari sebuah gambar[2][3][4][5][6][9]. Pada metode pengenalan gambar seperti HMM sebelum melakukan proses pengenalan diperlukan proses segmentasi. Proses segmentasi sebuah karakter dalam sebuah gambar merupakan proses yang rumit.. Hal ini dikarenakan untuk melakukan proses tersebut diperlukan pola-pola tertentu sehingga karakter tersebut dapat dipisahkan dengan karakter lain dalam sebuah gambar dan $\mathrm{CNN}$ dapat melakukan proses tersebut dengan baik [1][2][4]. Dalam melakukan proses pengenalan sebuah gambar $\mathrm{CNN}$ tidak memperlukan proses segmentasi[1]. Hal ini dikarenekan di dalam CNN terdapat arsitektur Lenet yang mampu mengenali sebuah karakter secara mandiri[5]. Di dalam [3], CNN digunakan untuk mendeteksi angka latin dari sebuah gambar. Selain itu pada [5] menunjukkan bahwa CNN dapat menunjukkan hasil yang positif saat digunakan untuk mengenali angka jawa. Pada penelitian lain $\mathrm{CNN}$ juga menunjukan hasil yang positif ketika digunakan untuk aksara non latin seperti huruf thailand [6] dan huruf india[2][8]. Penelitian ini berfokus pada klasifikasi gambar aksara jawa ngelena yang dicetak tanpa sandhangan maupun pasangan. Penelitian ini bertujuan agar aksara jawa ngalena (hanacaraka) tidak hilang tergerus zaman. Sekaligus dapat menjadi bukti bahwa kemajuan teknologi dapat tumbuh beriringan dengan kebudayaan.

\subsection{Penelitian Sebelumnya}

Penelitian yang sejenis pernah dilakukan sebelumnya [1] menggunakan metode HMM. Hasil yang didapat pada penilitian ini sebesar $85.7 \%$. Pada penelitian ini dataset yang digunakan tulisan tangan aksara jawa dengan jumlah dataset sebesar 1000, dengan rincian 800 sebagai datatraining dan 200 sebagai data testing. Jumlah aksara yang digunakan sebanyak 20 kata.

Penggunaan Convolution Neural Network dan untuk proses recoknisi untuk aksara jawa [9] menunjukkan hasil yang cukup meyakinkan. Hasil yang didapat nilai sebesar $70.22 \%$ and $64.65 \%$ for $\mathrm{CNN}$ and DNN. Dataset yang digunakan tulisan tangan aksara jawa sejumlah 2470 untuk 20 kelas. Di setiap kelasnya terdapat 123. Ukuran gambar yang digunakan sebesar 32 x 32 piksel

Dengan berbekal kelebihan tersebut penulis mencoba untuk menggunakan $\mathrm{CNN}$ dalam proses klasifikasi aksara hanacaraka. Aksara hanacaraka terdiri dari 20 huruf dimana huruf ini akan menjadi kelas yang nantinya.

\section{METODE}

\subsection{Pengumpulan Data}

Data yang digunakan dalam penelitian ini adalah gambar aksara jawa ngalena. Gambar aksara jawa terdiri dari 20 kelas, masing-masing kelas mempunyai 300 gambar. Dataset ini dibuat dari dua font Microsoft Word. Font yang digunakan adalah font Hanacaraka dan Tuladha Jejeg. Ukuran font hanacaraka sebesar 48 pt dan ukuran font untuk tuladha jejeg sebesar 64 pt. Kedua Font tersebut dicetak kemudian hasil cetak tadi discan kemudian dipotong tiap aksara. Untuk contoh gambar dataset bisa dilihat pada gambar 1 dan gambar 2 .

กาบก ที บากา มาบ

นดก กดฉ IRMก กிบ1

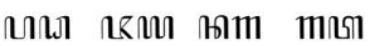

ஜிாก คிபி บกภ ทா

Gambar 1. Contoh Dataset Font Hanacaraka 
ता ณ का था ता

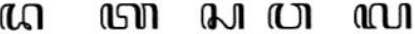

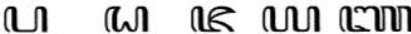

\section{छย ลก สุก ดุ กา}

\section{Gambar 2. Contoh Dataset Font Tuladha Jejeg}

\section{2. $\mathrm{CNN}$}

CNN secara sederhana merupakan sebuah jaringan saraf tiruan yang menggunakan matriks perkalian konvolusi di dalam arsitekturnya. Fungsi konvolusi di dalam CNN digunakan untuk ekstraksi fitur, dan dari proses ini nantinya akan menghasilkan fitur-fitur tertentu yang akan diproses multilayer perceptron untuk menghasilkan sebuah output dari inputan. Ada tiga proses utama yang ada di dalam layer konvolusi, yaitu konvolusi, subsampling / pooling, dan activation ReLu [6].

Di dalam CNN, Pooling Layer merupakan arraydengan ukuran $2 \times 2$ dan array ini akan berjalan ke setiap element pixel dari feature map ketika proses pengolahan citra sedang berlangsung. Di dalam penelitian ini Max Pooling digunakan untuk mengamnbil nilai tertinggi dari tiap element pixel yang mengalami proses konvolusi. Max Pooling digunakan dengan tujuan untuk mengurangi dimensi gambar sehingga proses training lebih cepat dan mengurangi overfitting [8]. Di dalam arsitektur CNN terdapat model yang disebut Lenet.

Lenet digunakan sebagai model yang dapat melakukan proses pengenalan sebuah gambar dengan proses ekstraksi fitur secara otomatis[2][3][4][5][6][8]. Lenet muncul setelah proses training. Bila sebuah hasil testing mengalami overfit maupun underfit maka dipastikan ada kesalahan pada proses training tersebut. Struktur lenet dapat digambarkan sebagai berikut

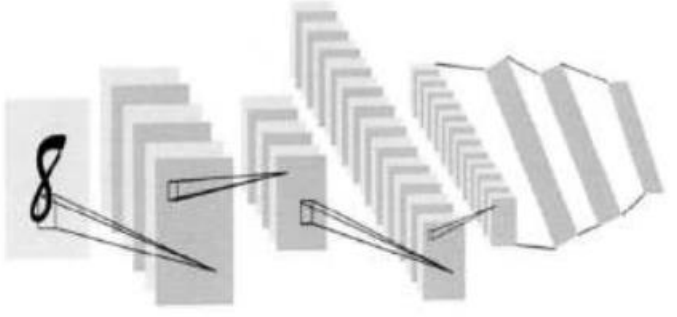

Gambar 3. Alur Lenet
Dalam penelitian ini, menggunakan dataset sebanyak 6000 gambar aksara jawa. Dataset tersebut dibagi menjadi dua yaitu sebagai trainingset dan testingset seperti pada gambar 1 . Untuk trainingset berjumlah 4000 dan testingset berjumlah 2000.Dataset yang digunakan dalam penelitian ini merupakan akasara jawa ngalena seperti sampel dalam Gambar 1. Dataset mempunyai dimensi 32x32 pixel.

Dataset terdiri dari 20 kelas, yaitu kelas ha,na,ca,ra,ka,da,ta,sa,wa,la,pa,dha,ja,ya,nya,ma,ga ,ba,tha,nga. Dataset ini yang digunakan dalam penelitian ini tersedia dalam Lampiran. Arsitektur model yang digunakan untuk rekognisi karakter dari citra dataset adalah LeNet. Diagram blok model LeNet ini ditunjukkan dalam Gambar 2. Lenet digunakan menggunakan ukuran masukan

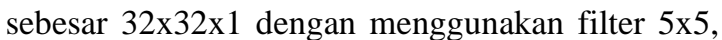
1 strides dan 0 pool. Dari ukuran matriks $32 \times 32$ dilakukan pembentukan matriks konvolusi menggunakan Persamaan 1 dan Persamaan 2. Matriks konvolusi mempunyai ukuran 28x28. Proses diskretisasi dilakukan berdasarkan sampel menggunakan maxpooling2D menggunakan filter 2x2 seperti ditunjukkan dalam Gambar 2 .

Setelah traningset diproses melalui CNN maka muncul sebuah model. Model yang dihasilkan inilah yang digunakan untuk melakukan proses pada testingset. Sehingga pada tahap prediksi bagus atau tidaknya hasil dikarenakan pada model yang dihasilkan. Apabila menghasilkan model yang baik, maka hasil akan baik. Proses penelitian ini dapat dilihat pada gambar 4.

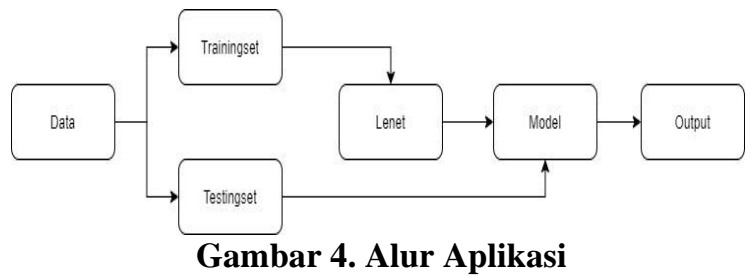

\section{PEMBAHASAN}

Pada tahap ini percobaan yang direncanakan pada bab sebelumnya dilakukan. Percobaan berfokus pada kemampuan CNN dalam melakukan klasifikasi gambar menjadi 20 kelas yaitu ha,na ca, ra, ka, da, ta, sa, wa, la, pa, dha, ja, ya, nya,ma, ga, bha, tha dan nga. Seluruh tahapan pada penelitian ini dijalankan pada notebook yang menggunakan processor core i5 dan Ram 4GB dengan menggunakan environment Anaconda, framework keras dan library tensorflow.

Pada penelitian ini epoch yang digunakan untuk membuat sebanyak 100. Untuk nilai ukuran pool 
yang digunakan sebesar 32 x 32 dan 64 x 64 . Sementara fitur matrix konvolusi yang digunakan adalah 32 × 32, 64 × 64 dan 128 × 128 . Hasil penelitian ini dapat dilihat pada tabel 1 .

Tabel 1 Hasil Pengenalan Aksara Jawa Menggunakan CNN

\begin{tabular}{lrrrrrrrr}
\hline & $\mathrm{Ha}$ & $\mathrm{Na}$ & $\mathrm{Ca}$ & $\mathrm{Ra}$ & $\mathrm{Ka}$ & $\mathrm{Da}$ & $\mathrm{Ta}$ & $\mathrm{Sa}$ \\
\hline $\mathrm{Ha}$ & 65 & 2 & 2 & 2 & 0 & 2 & 2 & 2 \\
$\mathrm{Na}$ & 4 & 60 & 4 & 2 & 0 & 2 & 2 & 2 \\
$\mathrm{Ca}$ & 4 & 0 & 61 & 2 & 2 & 6 & 2 & 2 \\
$\mathrm{Ra}$ & 1 & 4 & 2 & 55 & 2 & 3 & 2 & 4 \\
$\mathrm{Ka}$ & 2 & 4 & 2 & 2 & 56 & 2 & 2 & 4 \\
$\mathrm{Da}$ & 2 & 2 & 5 & 4 & 2 & 53 & 2 & 2 \\
$\mathrm{Ta}$ & 1 & 2 & 3 & 5 & 4 & 2 & 53 & 2 \\
$\mathrm{Sa}$ & 2 & 2 & 2 & 2 & 2 & 4 & 2 & 60 \\
$\mathrm{Wa}$ & 4 & 2 & 2 & 2 & 6 & 2 & 2 & 6 \\
$\mathrm{La}$ & 3 & 5 & 2 & 4 & 0 & 2 & 4 & 2 \\
$\mathrm{~Pa}$ & 4 & 2 & 2 & 5 & 2 & 2 & 3 & 2 \\
$\mathrm{Dha}$ & 2 & 2 & 2 & 7 & 2 & 2 & 0 & 2 \\
\hline
\end{tabular}

Tabel 1 Hasil Pengenalan Aksara Jawa Menggunakan CNN (Lanjutan)

\begin{tabular}{lrrrrrrrr}
\hline & $\mathrm{Ha}$ & $\mathrm{Na}$ & $\mathrm{Ca}$ & $\mathrm{Ra}$ & $\mathrm{Ka}$ & $\mathrm{Da}$ & $\mathrm{Ta}$ & $\mathrm{Sa}$ \\
\hline $\mathrm{Ja}$ & 5 & 2 & 2 & 0 & 2 & 2 & 2 & 4 \\
$\mathrm{Ya}$ & 2 & 2 & 2 & 0 & 2 & 4 & 2 & 2 \\
$\mathrm{Nya}$ & 3 & 6 & 2 & 5 & 4 & 5 & 0 & 0 \\
$\mathrm{Ma}$ & 2 & 2 & 2 & 0 & 8 & 0 & 2 & 4 \\
$\mathrm{Ga}$ & 2 & 2 & 2 & 2 & 2 & 2 & 2 & 2 \\
$\mathrm{Ba}$ & 2 & 2 & 2 & 2 & 2 & 2 & 2 & 2 \\
$\mathrm{Tha}$ & 2 & 2 & 4 & 2 & 2 & 2 & 4 & 2 \\
$\mathrm{Nga}$ & 1 & 2 & 4 & 3 & 4 & 2 & 4 & 2 \\
\hline
\end{tabular}

Tabel 1 Hasil Pengenalan Aksara Jawa Menggunakan CNN (Lanjutan)

\begin{tabular}{|c|c|c|c|c|c|c|c|c|c|c|}
\hline & $\mathrm{Wa}$ & $\mathrm{La}$ & $\mathrm{Pa}$ & Dha & $\mathrm{Ja}$ & $\mathrm{Ya}$ & Nya & Ma & $\mathrm{Ga}$ & Tha \\
\hline $\mathrm{Ha}$ & 2 & 2 & 2 & 2 & 2 & 2 & 1 & 0 & 2 & $\mathrm{Nga}$ \\
\hline $\mathrm{Na}$ & 2 & 3 & 2 & 2 & 2 & 4 & 2 & 2 & 4 & \\
\hline $\mathrm{Ca}$ & 8 & 2 & 2 & 0 & 0 & 2 & 2 & 4 & \multirow{6}{*}{\multicolumn{2}{|c|}{$\begin{array}{l}\text { diketahui bahwa hasil y } \\
\text { Berkisar dari } 48 \text { hingga } 6 \\
\text { Presisi, recall dan } f \text {-mea } \\
\text { Bisa dilihat pada (1), untu } \\
\text { @ada (2) sedangkan unt } \\
\text { Qilihat pada (3). }\end{array}$}} \\
\hline $\mathrm{Ra}$ & 2 & 4 & 2 & 2 & 3 & 2 & 4 & 0 & & \\
\hline $\mathrm{Ka}$ & 2 & 4 & 2 & 2 & 2 & 2 & 2 & 2 & & \\
\hline $\mathrm{Da}$ & 2 & 2 & 2 & 6 & 2 & 2 & 2 & 2 & & \\
\hline $\mathrm{Ta}$ & 2 & 2 & 0 & 0 & 0 & 8 & 4 & 2 & & \\
\hline $\mathrm{Sa}$ & 2 & 2 & 2 & 2 & 2 & 2 & 2 & 2 & & \\
\hline Wa & 50 & 5 & 2 & 0 & 0 & 0 & 2 & 2 & \multirow{2}{*}{\multicolumn{2}{|c|}{${ }^{6}$ presisi $=\frac{\text { total benar }}{\text { total terprediksi }}$}} \\
\hline $\mathrm{La}$ & 2 & 55 & 3 & 4 & 6 & 1 & 4 & 3 & & \\
\hline $\mathrm{Pa}$ & 2 & 2 & 53 & 2 & 0 & 0 & 4 & 2 & 2 & \\
\hline Dha & 2 & 4 & 2 & 57 & 2 & 2 & 2 & 2 & 2 & \\
\hline
\end{tabular}

Tabel 1 Hasil Pengenalan Aksara Jawa Menggunakan CNN (Lanjutan)

\begin{tabular}{lrrrrrrrrr}
\hline & Wa & La & Pa & Dha & Ja & Ya & Nya & Ma & Ga \\
\hline $\mathrm{Ja}$ & 5 & 2 & 6 & 2 & 53 & 0 & 4 & 7 & 4 \\
$\mathrm{Ya}$ & 2 & 2 & 2 & 2 & 2 & 62 & 2 & 2 & 2 \\
$\mathrm{Nya}$ & 7 & 2 & 6 & 2 & 2 & 4 & 60 & 2 & 2 \\
$\mathrm{Ma}$ & 7 & 2 & 2 & 2 & 2 & 5 & 2 & 58 & 2 \\
$\mathrm{Ga}$ & 2 & 1 & 2 & 2 & 4 & 2 & 2 & 2 & 61 \\
$\mathrm{Ba}$ & 6 & 4 & 2 & 2 & 2 & 2 & 2 & 2 & 2 \\
$\mathrm{Tha}$ & 6 & 2 & 2 & 2 & 2 & 2 & 2 & 2 & 2 \\
$\mathrm{Nga}$ & 4 & 2 & 3 & 3 & 2 & 0 & 0 & 2 & 6 \\
\hline
\end{tabular}

Tabel 1 Hasil Pengenalan Aksara Jawa Menggunakan CNN (Lanjutan)

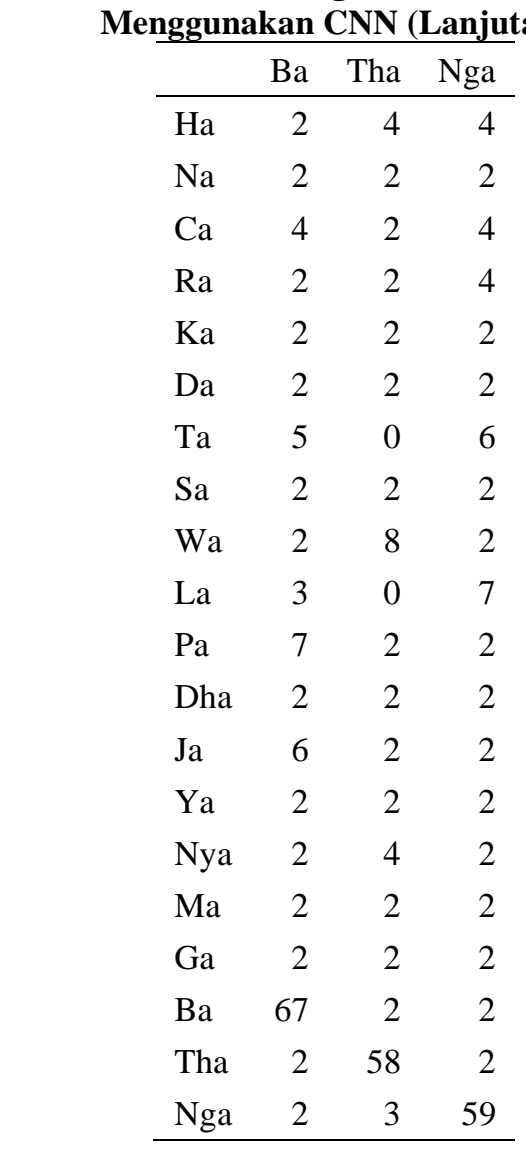

tabel 1 bisa 
recall $=\frac{\text { total benay }}{\text { total data }}$

$f-$ measure $=\frac{2 \text { xpresisixrecall }}{\text { presisi }+ \text { recall }}$

Presisi merupakan rasio prediksi benar positif dibandingkan dengan keseluruhan hasil yang diprediksi positif. Recall merupakan rasio prediksi benar positif dibandingkan dengan keseluruhan data yang benar positif. Sedangkan $f$-measure merupakan perbandingan rata-rata presisi dan recall yang dibobotkan. Untuk mengetahui nilai presisi, recall dan $f$-measure dari tabel 1 bisa dilihat pada tabel 2 .

Tabel 2 Hasil Presisi, Recall dan F-measure

\begin{tabular}{cccc}
\hline & Presisi & Recall & F-measure \\
\hline $\mathrm{Ha}$ & 0,58 & 0,64 & 0,61 \\
$\mathrm{Na}$ & 0,57 & 0,59 & 0,58 \\
$\mathrm{Ca}$ & 0,56 & 0,6 & 0,58 \\
$\mathrm{Ra}$ & 0,52 & 0,54 & 0,53 \\
$\mathrm{Ka}$ & 0,54 & 0,55 & 0,55 \\
$\mathrm{Da}$ & 0,53 & 0,52 & 0,53 \\
$\mathrm{Ta}$ & 0,57 & 0,52 & 0,55 \\
$\mathrm{Sa}$ & 0,56 & 0,59 & 0,58 \\
$\mathrm{Wa}$ & 0,43 & 0,5 & 0,47 \\
$\mathrm{La}$ & 0,53 & 0,54 & 0,54 \\
$\mathrm{~Pa}$ & 0,54 & 0,52 & 0,53 \\
$\mathrm{Dha}$ & 0,6 & 0,56 & 0,58 \\
$\mathrm{Ja}$ & 0,59 & 0,52 & 0,56 \\
$\mathrm{Ya}$ & 0,6 & 0,61 & 0,61 \\
$\mathrm{Nya}$ & 0,58 & 0,59 & 0,59 \\
$\mathrm{Ma}$ & 0,58 & 0,57 & 0,58 \\
$\mathrm{Ga}$ & 0,54 & 0,6 & 0,57 \\
$\mathrm{Ba}$ & 0,56 & 0,66 & 0,61 \\
$\mathrm{Tha}$ & 0,57 & 0,57 & 0,57 \\
$\mathrm{Nga}$ & 0,53 & 0,58 & 0,56 \\
$\mathrm{AVG}$ & $\mathbf{0 , 5 6}$ & $\mathbf{0 , 5 7}$ & $\mathbf{0 , 5 7}$ \\
\hline & & &
\end{tabular}

Dari hasil tabel 2 dapat dilihat bahwa dari 20 kelas yang diklasifikasikan didapatkan sebagai berikut nilai rata-rata presisi, recall dan F-measure sebesar 0.53 .

\section{KESIMPULAN}

Klasifikasi huruf cetak aksara jawa yang dilakukan dengan menggunakan metode Convolution Nueral Network dan menggunakan 6000 dataset mendapatkan nilai rata-rata presisi sebesar 0.56 , untuk nilai rata-rata recall sebesar 0.56 dan untuk nilai rata-rata $F$-measure sebesar 0.57 .
Dengan hasil yang didapat, dapat disimpulkan bahwa metode CNN cukup handal.

Pada penelitian ini tentu masih banyak memiliki kekurangan. Kedepan akan perlu perbaikan dalam penelitian selanjutnya. Pada penelitia berikutnya dapat ditambahkan metode preprocessing sehingga diharapkan mendapatkan nilai yang lebih tinggi dari penelitian ini.

\section{PUSTAKA}

A. Rita Widiarti and P. Nari Wastu, "Javanese Character Recognition Using Hidden Markov Model," International Science Index, Computer and Information Engineering Vol:3, No:9, 2009.

Bishwajit Purkaystha, Tapos Datta and Md Saiful Islam, "Bengali Handwritten Character Recognition Using Deep Convolutional Neural Network," 2017 20th International Conference of Computer and Information Technology. ICCIT 2017.

Huiqun Deng, George Stathopoulos, and Ching Y. Suen, "Applying Error-Correcting Output Coding to Enhance Convolutional Neural Network for Target Detection and Pattern Recognition",International Conference on Pattern Recognition. 2010.

Kietikul Jearanaitanakij and Ouen Pinngern "Hidden Unit Reduction of Artificial Neural Network on English Capital Letter Recognition" IEEE, 2006, doi: 1-4244-0023-6/06/\$20.00.

Kun Guo, Ning Li, "Research on Classification of Architectural Style Image Based on Convolution Neural Network," 2017 IEEE, doi: 978-1-50905363-6/17/\$31.00.

Phatthanaphong Chomphuwiset "Printed Thai Character Segmentation and Recognition," 2017 4th IEEE International Conference on Soft Computing and Machine Intelligence.

Rismiyati, Khadijah, and A. Nurhadiyatna, "Deep learning for handwritten Javanese character recognition," Proc. - 2017 1st Int. Conf. Informatics Comput. Sci. ICICoS 2017, vol. 2018-January, pp. 59-63, 2018, doi: 10.1109/ICICOS.2017.8276338.

Roshan Fernandes and Anisha P Rodrigues, "Kannada Handwritten Script Recognition using Machine Learning Techniques," 2019 IEEE, doi: 978-1-7281-3735-3/19/\$31.00.

T. Septianto, E. Setyati, and J. Santoso, "Digit Classification of Majapahit Relic Inscription using GLCM-SVM," vol. 1, no. 2, pp. 46-54, 2018. 